\title{
PENGARUH PURSED LIP BREATHING DAN SUSTAINED MAXIMAL INSPIRATION TERHADAP PENINGKATKAN KEKUATAN OTOT PERNAPASAN UNTUK MENGURANGI KELUHAN SESAK NAPAS PADA KASUS KARDIO RESPIRASI
}

\author{
Agung Wahyu Permadi, Antonius Tri Wahyudi \\ Program Studi Fisioterapi Universitas Dhyana Pura Badung Bali Indonesia
}

\begin{abstract}
Sustained Maximal Inspiration, Pursed Lip Breathing, Shortness Of Breath. Currently lung disease is a major cause of chronic morbidity and mortality worldwide, many people suffer from this disease for many years and die prematurely due to unhealthy lifestyles such as smoking and work environments that are exposed to much air pollution due to under-employed workers personal protector. One sign of lung disease is airway obstruction in nonreversible or partial reversible airway. One result of lung disease is a lack of respiratory muscle strength resulting in complaints of shortness of breath. Disturbances or complaints of breathlessness can occur towards inspiration or expiration. There is a theory of the effect of breathing exercises on respiratory muscle enhancement in people with shortness of breath. In this study was conducted with the aim to prove the provision of Sustained maximal inspiration (SMI) and pursed lip breathing (PLB) to increase respiratory muscle strength in patients with shortness of breath. This research uses true experimental research with pre-test and post-test design. The study was conducted at the physiotherapy laboratory located in Tabanan, Badung and Denpasar with a sample of 17 patients who experienced complaints of shortness of breath. The number of research subjects was grouped randomly in one group. In this study the group was given treatment as much as 1 time a week and performed for 24 weeks. The expected result of this study was to reduce complaints of shortness of breath without the use of medicines from doctors in cases of cardio respiration
\end{abstract}

Keywords: Sustained Maximal Inspiration, Pursed Lip Breathing, Shortness Of Breath.

\begin{abstract}
Abstrak : Sustained Maximal Inspiration, Pursed Lip Breathing, Keluhan Sesak Napas. Saat ini penyakit paru merupakan penyebab utama morbiditas dan mortalitas kronis di seluruh dunia, banyak orang menderita penyakit ini selama bertahun-tahun dan mati sebelum waktunya akibat pola hidup yang tidak sehat seperti merokok dan lingkungan kerja yang banyak terpapar polusi udara akibat pekerja yang kurang menggunakan alat pelindung diri. Salah satu tanda dari penyakit paru adalah hambatan aliran udara di saluran napas yang bersifat progresif nonreversible atau reversible parsial. Salah satu akibat dari penyakit paru ialah kurangnya keuatan otot pernapasan yang berakibat mengeluh sesak napas. Gangguan atau keluhan sesak napas dapat terjadi ke arah inspirasi maupun ekspirasi. Terdapat teori adanya pengaruh latihan pernapasan terhadap peningkatan otot pernapasan pada penderita keluhan sesak napas. Pada penelitian ini dilakukan dengan tujuan untuk membuktikan pemberian Sustained maximal inspiration (SMI) dan pursed lip breathing (PLB) terhadap peningkatan
\end{abstract}


kekuatan otot pernapasan pada pasien dengan keluhan sesak napas. Penelitian ini menggunakan Penelitian true eksperimental dengan rancangan penelitian pre-test dan post-test design. Penelitian dilaksanakan di laboratorium fisioterapi yang berada di daerah Tabanan, Badung dan Denpasar dengan sampel 17 pasien yang mengalami adanya keluhan sesak napas. Jumlah subyek penelitian dikelompokkan secara acak dalam satu kelompok. Dalam penelitian ini kelompok diberikan perlakuan sebanyak 1 kali seminggu dan dilakukan selama 24 minggu. Hasil yang diharapkan dari penelitian in adalah untuk mengurangi keluhan sesak napas tanpa menggunakan obat-obatan dari dokter pada kasus kardio respirasi

Kata Kunci : Sustained Maximal Inspiration, Pursed Lip Breathing, Keluhan Sesak Napas.

\section{PENDAHULUAN}

Penyakit paru merupakan penyebab kematian terbesar di dunia. Berdasarkan data World Life Expectancy tahun 2012, Indonesia termasuk negara dengan tingkat kematian akibat penyakit paru-paru tertinggi di dunia. Dalam daftar lembaga survei kesehatan internasional, Indonesia menduduki peringkat ke-14 dari 192 negara yang disurvei. Tingkat kematian akibat penyakit paru di negara ini terus meningkat mencapai 53 orang per 100.000 penduduk setiap tahun. Sebagai perbandingan, tingkat kematian di Vietnam jauh lebih kecil daripada Indonesia, yakni 46 orang per 100.000 penduduk (Gold, 2005). Kematian disebabkan oleh penyakit paru seperti PPOK, atelektasis, dan gangguan sistem pernapasan lainnya.

Penyakit paru adalah penyakit yang ditandai oleh hambatan aliran udara di saluran nafas yang bersifat progresif nonreversible atau reversible parsial. Menurut WHO yang dituangkan dalam Global Initiative for chronic Obstructive Lung Disease (GOLD) tahun 2015, penyakit kardio respirasi didefenisikan sebagai penyakit yang ditandai oleh adanya obstruksi saluran pernapasan yang tidak reversible sepenuhnya. Sumbatan aliran udara ini umumnya bersifat progresif dan berkaitan dengan proses inflamasi abnormal paru-paru terhadap partikel atau gas yang berbahaya. Salah satu faktor gangguan yang sering dialami oleh penderita kasus kardio respirasi adalah sesak napas. Sesak napas ini dapat terjadi ke arah inspirasi maupun ekspirasi. Gangguan ke arah inspirasi biasanya ditemukan pada kasus penyakit paru seperti fibrotik pulmonary, haemothorak, dan pneumothorak. sedangkan gangguan ke arah ekspirasi ditemukan pada kasus penyakit paru obstruktif misalnya PPOK (Basuki, 2008). Peneliti menggunakan intervensi latihan napas dalam yang ditahan atau sustained maximal inspiration yang bertujuan untuk meningkatkan volume paru, meningkatkan oksigenasi, mempertahankan alveolus tetap mengembang, membantu membersihkan sekresi, memobilisasi sangkar torak dan meningkatkan kekuatan dan daya tahan serta efisiensi dari otot otot pernapasan (Basuki, 2008). Sedangkan pursed lip breathing dengan tujuan untuk mempermudah proses pengeluaran udara yang terjebak oleh saluran napas dalam upaya meningkatkan kekuatan otot pernapasan yang terfokus pada latihan ekspirasi (Basuki, 2008). 
Penelitian Schans pada tahun 2007 tentang pengaruh konvensional chest physiotherapy pada 79 pasien dengan PPOK, membandingkan kelompok kontrol yang hanya diberi terapi medika mentosa dengan kelompok perlakuan yang diberi terapi medika mentosa ditambah terapi konvensional chest physiotherapy. Hasilnya tidak ada perbedaan yang signifikan pada nilai prediksi FEV1.

Penelitian ini mencoba membuktikan tentang prosedur penatalaksanaan intervensi fisioterapi pada kasus penyakit paru agar diketahui pengaruh intervensi pursed lip breathing dan sustained maximal inspiration terhadap peningkatan kekuatan otot pernapasan dalam mengurangi keluhan sesak napas.

Dispnea atau sesak napas adalah perasaan sulit bernapas ditandai dengan napas yang pendek dan penggunaan otot bantu pernapasan. Dispnea dapat ditemukan pada penyakit kardiovaskular, emboli paru, penyakit paru interstisial atau alveolar, gangguan dinding dada, penyakit obstruktif paru (emfisema, bronkitis, asma), kecemasan (Price dan Wilson, 2006). Menurut Nur Basuki tahun 2008, sesak napas memiliki pengertian perasaan yang dirasakan oleh seseorang mengenai ketidaknyamanan atau kesulitan dalam bernapas.

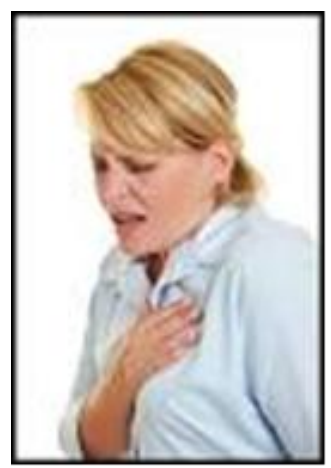

Gambar Sesak Napas (PDPI, 2008)
PLB merupakan latihan pernapasan yang menekankan pada proses ekspirasi yang dilakukan secara tenang dan rileks dengan tujuan untuk mempermudah proses pengeluaran udara yang terjebak oleh saluran napas (Nerini, dkk. 2011). Melalui teknik ini, maka udara yang ke luar akan dihambat oleh kedua bibir, yang menyebabkan tekanan dalam rongga mulut lebih positif. Tekanan posistif ini akan menjalar ke dalam saluran napas yang menyempit dan bermanfaat untuk mempertahankan saluran napas untuk tetap terbuka. Dengan terbukanya saluran napas, maka udara dapat ke luar dengan mudah melalui saluran napas yang menyempit serta dengan mudah erpengaruh pada kekuatan otot pernapasan untuk mengurangi sesak napas (Alsagaf, 2012).

Latihan napas dalam atau sustained maximal inspiration merupakan teknik latihan pernapasan (breathing exercise) yang menekankan pada inspirasi maksimum ditambah dengan penahanan pada akhir inspirasi sebanyak tiga detik maksimal yang panjang yang dimulai dari akhir ekspirasi (Basuki, 2008). Selama latihan napas dalam yang ditahan, udara yang masuk ke paru-paru tidak didistribusikan secara merata. Hal ini disebabkan karena penurunan tekanan intrapleural yang disebabkan oleh gravitasi, tekanan dari dinding torak dan paru yang akan menyebabkan alveolus di bagian dependen paru lebih mengecil dibandingkan dengan bagian independen. Oleh karena itu, jika pernapasan dilakukan dengan pernapasan tenang, maka distribusi udara akan lebih banyak pada daerah dependen paru. Namun demikian, jika pernapasan dilakukan pada volume paru yang besar (very high lung volume) distribusi akan lebih merata, hal ini 
disebabkan karena alveolus menjadi kurang compliant. Kebalikannya, jika pernapasan diselenggarakan pada volume paru yang lebih kecil (low lung volume), maka distribusi udara hanya terjadi pada daerah independen saja. Hal tersebut disebabkan pada daerah dependen terjadi penutupan saluran napas, sehingga udara tidak bisa masuk ke daerah dependen. Keadaan ini akan mempermudah timbulnya atelektasis terutama pada kasus pasca operasi yang menyebabkan turunnya volume paru termasuk pada kasus hemotorak. Ferris dan Pollard tahun 2006 melaporkan bahwa latihan napas dalam yang ditahan sebanyak lima kali berurutan dapat meningkatkan kekuatan otot pernapasan untuk mengurangi sesak napas pada penyakit paru obstruktif kronis.

\section{METODE PENELITIAN}

Data yang digunakan dalam penelitian ini adalah data kuantitatif. Data kuantitatif adalah data yang berbentuk bilangan atau angka yang dapat dilakukan perhitungan dengan alat bantu statistik, diantaranya adalah data yang diukur dari keluhan sesak napas yang diukur melalui skala BORG. Pasien akan memberikan pilhan sesuai apa yang dirasakan yang ditampilakn dalam skala $B O R G$ tersebut. Berdasarkan sumbernya, data dalam penelitian ini diambil dari sumber data primer dan data sekunder. Data primer adalah data yang dikumpulkan langsung dari pengambil data kepada pasien. Data sekunder dikumpulkan dari dokumentasi mengenai selisih antara inspirasi dan ekspirasi maksimal. Dalam penelitian ini data dikumpulkan melalui teknik sebelum perlakuan dan setelah perlakuan.

Analisis data yang digunakan dalam penelitian menggunakan bantuan
SPSS. Analisis ini digunakan untuk memberikan penggambaran hasil penelitian di lapangan tanpa harus memanipulasi fakta yang riil. Data dari kelompok akan di uji normalitasnya dengan Shapiro Wilk-Test dengan tingkat kemaknaan 0,05. Jika normal data akan dianalisis dengan statistik parametrik dan jika data tidak normal dianalisis menggunakan statistik non parametrik. Uji antar kelompok ini menggunakan Levene's Test untuk mendapatkan gambaran tentang homogenitas.

\section{HASIL PENELITIAN}

Penelitan telah dilaksanakan di tempat laboratorium fisioterapi yang berada di daerah Tabanan, Badung dan Denpasar selama 3 bulan terhadap 17 orang subyek penelitian dan jenis penelitian yang dipakai adalah one groups pre and post test design yang menggunakan data kuantitatif dengan menggunakan statistik deskriptif. Sebagai prasyarat untuk menentukan uji statistik yang digunakan, maka dilakukan uji normalitas dan homogenitas data hasil pengembangan sangkar torak sebelum dan setelah perlakuan. Uji normalitas data menggunakan uji Shapiro Wilk-Test, sedangkan uji homogenitas menggunakan Lavene's Test.

\section{PEMBAHASAN}

Berdasarkan hasil uji normalitas (Shapiro Wilk-Test) data menunjukkan nilai $\mathrm{p}$ lebih kecil dari 0,05 ( $\mathrm{p}>0,05)$, yang berarti data sebelum dan setelah perlakuan berdistribusi tidak normal. Hal ini dikarenakan jumlah sampel tidak banyak atau kecil. Sedangkan uji homogenitas (Lavene's Test) dari kelompok perlakuan menunjukkan $\mathrm{p}>$ 
0,05 yang menunjukkan data bersifat homogen.

\section{Tabel 1}

Uji Normalitas

\begin{tabular}{|c|c|c|c|c|}
\hline & & \multicolumn{3}{|c|}{ Shapiro-Wilk } \\
\hline $\begin{array}{l}\text { pre pursed lip } \\
\text { breathing }\end{array}$ & & $\begin{array}{r}\text { Statistic } \\
, 874\end{array}$ & $\begin{array}{l}\mathrm{df} \\
17\end{array}$ & Sig. \\
\hline $\begin{array}{l}\text { post pursed lip } \\
\text { breathing }\end{array}$ & &, 839 & 17 & \\
\hline $\begin{array}{l}\text { Levene } \\
\text { Statistic } \\
, 669\end{array}$ & $\mathrm{df1}_{1}$ & $\begin{array}{c}\mathrm{df} 2 \\
32\end{array}$ & & \\
\hline & & $\begin{array}{l}\text { post purse } \\
\text { eathing - pr } \\
\text { lip breat }\end{array}$ & $\begin{array}{l}\text { d lip } \\
\text { e pur } \\
\text { ing }\end{array}$ & \\
\hline$Z$ & & & -3.7 & \\
\hline $\begin{array}{l}\text { Asymp. Sig. } \\
\text { (2-tailed) }\end{array}$ & & & & 00 \\
\hline
\end{tabular}

Berdasarkan analisis data yang tidak berdistribusi normal, maka untuk uji hiptesis digunakan uji Wilcoxon. Didapat hasil beda rerata peurunan keluhan sesak napas sebelum dan setelah perlakuan memiliki nilai $\mathrm{p}$ lebih kecil dari 0,05 ( $\mathrm{p}<$ $0,05)$. Hal ini menunjukkan bahwa terjadi peningkatan kekuatan otot sebelum dan setelah perlakuan secara bermakna. Dengan demikian ada Pengaruh pursed Lip Breathing dan sustained Maximal inspiration Terhadap Peningkatan Kekuatan Otot Pernapasan Untuk Mengurangi Keluhan Sesak Napas Pada Kasus Kardio Respirasi.

\section{KESIMPULAN DAN SARAN}

Dari penelitian yang dilakukan selama 24 minggu dengan dosis 2 kali dalam seminggu di laboratorium fisioterapi di daerah Tabanan, Badung dan Denpasar pada bulan Maret sampai
Agustus 2017 maka dapat diambil simpulan ada Pengaruh pursed Lip Breathing dan sustained Maximal inspiration Terhadap Peningkatan Kekuatan Otot Pernapasan Untuk Mengurangi Keluhan Sesak Napas Pada Kasus Kardio Respirasi.

Berdasarkan simpulan penelitian, disarankan beberapa hal yang berkaitan dengan pasien dega kasus kardio respirasi antara lain :

1) Hasil penelitian ini diharapkan mampu dipakai oleh penderita sebagai suatu cara yang sederhana dan mudah dilakukan serta tanpa menggunakan alat untuk meningkatkan kekuatan otot pernapasan untuk mengurangi keluhan sesak napas terutama pasien rawat jalan.

2) Karena pentingnya peningkatan kekuatan otot pernapasan peneliti menyarankan dilakukan penelitian lanjutan untuk mengetahui peningkatan kekuatan otot pada kasus kardio respirasi dengan jangka panjang dan jumlah sampel yang lebih banyak mengingat prevalensi dan mortalitasnya akan terus meningkat pada dekade mendatang dan lebih progresif dibandingkan paru yang normal pertahunnya.

\section{DAFTAR RUJUKAN}

Alsagaf. 2012. Dasar-dasar Ilmu Penyakit Paru. Surabaya: Airlangga Press.

Basuki, N. 2008 hand Out Fisioterapi pada kardiovaskulopulmonal. Surakarta. Jawa Tengah: Polteknik Kesehatan Surakarta.

Global Initiative for Chronic Obstructive Lung Disease (GOLD). 2015. Pocket Guide to COPD Diagnosis, Management, and Prevention. Dari http//www.goldcopd.org. diambil Juli 2015. 
240 Jurnal Terpadu Ilmu Kesehatan, Volume 6, No 2, November 2017, hlm 118-240

Nerini M, Gigliotti F, Lanini I, Grazzini M, Stendardi C, Castellani R, et al. 2009. Changes in global and compartmental lung volumes during pursed lip breathing (PLB) in COPD patients [abstract]. Eur Respir J 2001;18(Suppl 33):489. CITA.

PDPI. 2008. PPOK Pedoman Praktis Diagnosis dan Penatalaksanaan di Indonesia. Jakarta, hal.1-18. 